\title{
Efrosyni Boutsikas, Stephen C. McCluskey and John Steele (eds), Advancing Cultural Astronomy: Studies In Honour of Clive Ruggles
}

\author{
Springer International Publishing, 2021. Hardback 319 pages, illustrated, \\ ISBN: 978-3-030-64605-9. £109.99; eBook 978-3-030-64606-6. £87.50.
}

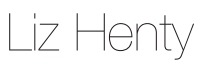

University of Wales Trinity Saint David

lizhenty2@gmail.com

Clive Ruggles' contribution to the field of cultural astronomy has been recognised in this book in his honour. It consists of fourteen chapters, written by some of today's leading archaeoastronomers, which focus on many aspects that Ruggles has highlighted during his lengthy career. There is a main preface written by the editors, with short prefaces for the three sections that make up the book: Methodology, Case Studies and Heritage. The editors - Efrosyni Boutsikas, Stephen C. McCluskey and John Steele - have all had a long association with Clive over many years and have chosen to celebrate him by putting together a volume to showcase what they feel is the best of cultural astronomy. In this they are to be commended, because editing a book like this requires a great deal of effort and hard work.

The preface attempts to be a fitting tribute, though it does contain some inaccuracies, such as citing the 1977 paper by Cooke, Few, Morgan and Ruggles as being his earliest work, when actually there had been a prior collaboration with Bailey and others in 1975, published in Nature (Bailey et al. 1975). The authors maintain that Ruggles' early work concentrated on setting out rigorous standards (no one could disagree with that) as well as dealing with the cultural context of the sites he surveyed. Yet, though this was undoubtedly his aim, the editors acknowledge that at that time he failed to come close to cultural explanations of British megalithic monuments (p. 2). This is not to deny Ruggles' huge importance to the field of archaeoastronomy, in its narrowest sense of verifying the statistical probability for the intentionality of alignments, together with his early recognition that many more questions needed to be asked. Ruggles' welcome repositioning away from his earlier statistical alignment studies separates his early research from the cultural astronomy that came later in his work, for example his work on Hawai'i (Kirch and Ruggles 2019), also mentioned in the preface. Also, there is no doubt that some of Ruggles' 
theoretical papers like "Whose Equinox?" (1997) have been seminal for the field, and this is rightly endorsed in the preface. When it comes to archaeology in Britain, as Hutton $(2013,389)$ pointed out, Ruggles is the archaeologists' go-to "voice of reason". The editors at this point only briefly treat Ruggles' impact in obtaining World Heritage status for sites of astronomical significance (though there is more on this in the preface to the heritage section), after which they seem to have run out of steam. There is no mention of Ruggles' editorship of the Archaeoastronomy Supplement of the Journal for the History of Astronomy, the only British journal that focused on archaeoastronomy, and nothing about the part he played in the foundation of the cultural astronomy associations of SEAC and ISAAC. He also initiated the first archaeoastronomy course in Britain at the University of Leicester, became the first and only Professor of Archaeoastronomy and wrote the first comprehensive textbook for the field (Ruggles 1999), as well as authoring or editing important books on archaeoastronomy and ethnoastronomy (Ruggles 2005, 2015). From these unmentioned facts alone it can be seen that Ruggles is primarily an educator publishing regular mission statements, largely to an audience of part-time and hobbyist archaeoastronomers (see for example Ruggles 2011) to try and advance the field. In a volume in his honour, these are glaring omissions.

The three parts of the book represent Ruggles' three areas of influence, though the line drawn to separate the papers between the sections is not clear at all. I feel that as "archaeoastronomy" as a term is somewhat passé, not as a methodology but as a name for the field, which is better served by the appellation "cultural astronomy", so I was curious to see how the authors of the main chapters had incorporated the cultural element into their studies. In the first chapter of the Methodology section, Juan Antonio Belmonte pays homage to Ruggles' equinox paper, mentioned above, by naming his contribution "What Equinox?". It asks whether the concept of the equinox is reliable and whether it should still be used in cultural astronomy studies. He goes on to examine three sites where alignment to the equinox has been claimed, discounting the case at Knowth in Ireland as "data overinterpretation" (p. 13), while suggesting alignments at other sites, such as the Maltese temples, could have happened by chance. Belmonte also reassessed a sample of 330 temples of ancient Egypt with similar findings. Indeed, despite many examples of architecture supposedly aligned to the equinoxes, the results are ambivalent and the lesson Belmonte stresses is the one he learnt at El Castillo at Chichen Itza in Yucatan: "do not go to observe a phenomenon like this only when preconceived ideas suggest, check alternatives" (p. 28).

Continuing with the equinox theme is John Steele's "Their Equinox: Mesopotamian Conceptions of Solstices and Equinoxes". From Babylonian texts dating to the second millennium BC it appears that the Babylonians were aware of a time of the year when nights and days are equal in length, which is what happens at the astronomical equinox. The Babylonians recognised that the length of day and night was connected to "four equally-spaced" dates in their calendar (p. 39), equivalent to our solstices and equinoxes. Steele points out that the calendar itself was schematic, because observation would have shown that these events would not have happened on the same date every year. From the seventh century BC, Neo-Assyrian texts recorded actual observations and introduced the idea of the Sun standing still at the solstices, whereas equinoxes are referred to as 
"balanced" (p. 44). The usefulness of this contribution is not so much the historical detail, which is quite technical, but the conclusion that "underlying concepts can be subtly different and we must not impose our understanding of one conception into the other culture" (p. 47). The editors had already pointed out this equinox theme, drawing attention to the chapters by Belmonte, Steele, Boutsakis and Ghezzi, but the last two authors are tucked away, Boutsakis in the Case Studies section and Ghezzi in the Heritage section - an ordering which to this reviewer is bizarre, to say the least.

Following the first two equinox papers, Stephen C. McCluskey takes us from Mesopotamian calendars to the Hopi calendar, without actually telling us where the Hopi live/ lived in northeastern Arizona. The Hopi devised a system of horizon markers (agricultural, ceremonial and cosmological) to regulate their activities throughout the year according to the position of the Sun along the horizon (p. 53). Ethnographic evidence, first collected in the nineteenth century and updated since has provided detail on the markers and their various uses. For example, the marker called Kwiitsala is used for the first day of planting corn (p. 62). Because of the changing topography the distances between the markers and the villages are not consistent, but they appear to be set out on the most distant visible ridge (p. 64). There is a preamble about why the Hopi markers do not conform with the categories listed by Alexander Thom in 1980 (Thom and Thom 1980) for British latitudes of $55^{\circ}$, which is like comparing chalk and cheese given the differences in topography: almost mountainous hills in Scotland and flat mesas in Arizona, with a latitude $20^{\circ}$ lower. Why? Maybe it's to warn readers of the next part of the chapter, which discusses the precision of the Hopi markers in minutes of arc - a method that thankfully became outdated following Ruggles' many criticisms of Thom. The Hopi cosmology seems to be culturally intuitive and adapted for their needs, so why would we even look for precision, let alone in minutes of arc? It seems anachronistic, especially given Steele's important conclusion, on p. 47 as cited above, about not interpreting other cultures through our own preconceptions.

It was a joy to be able to move on to the chapter by Alejandro López to read about the signs (netanec in the Moqoit language) of the Southwestern Chaco Moqoit peoples of Argentina, work informed by extensive ethnographic research. Their cosmology depends on power but not in the way the Western world conceives it: power is present in vegetables, animals, humans and rain, storms, lightning, meteorites and so on (p. 77). These are shape-shifting categories which can be transformed by power, not set apart by dualities such as animate/inanimate. The Moqoit cosmos is divided into three levels, "laua, the central plane that the Moqoit inhabit; the underworld; and the sky or piguem" (p. 78). Under this classification the sky is the place of abundance, inhabited by powerful feminine beings. The brightness of a star determines how powerful it is, and the sky is connected to the Earth through rainwater. Although the levels are distinct, they are interconnected through a giant tree called nallagdigua, which the Moqoit shamans can climb in their dreams. In this complex cosmology the Moqoit have derived a system of signs which are potent events that can be interpreted and applied according to the circumstances. Having explained the context of the Moqoit cosmology, López examines the signs in more detail; there are cosmic signs, signs that relate to the annual cycle, signs for leaders and decisions and signs to do with everyday life, which include signs ranging from the weather forecast 
to the reconciliation of couples or the death of a spouse (p. 93). Meteorites are also special signs which have different meanings. Overall, the conclusion is that the Moqoit inhabit a socio-cosmos into which López has allowed us to enter. If we could shrug off our Western ideas about archaeoastronomical alignments and think more anthropologically, as López does, we might arrive at a better understanding of the prehistoric and protohistoric cultures we routinely study.

The volume then leaps to the problems of translating ancient Greek geographical texts in a chapter by D. Graham J. Shipley. This is detailed research relating to how the Greek authors, such as Herodotus and Hipparchos, used several different words to describe the cardinal directions, the go-to points archaeoastronomers measure with their compasses. For example, west could be described as "sinking", "setting", "on the side of (the) setting sun" (p. 129). The descriptions of wind directions have similar celestial associations, so for instance north winds were described as "from the bear" (Ursa Major of course) or from the "hemisphere towards Boreas" (the Greek god denoting the north wind). There are so many hidden cosmological meanings in the words, which in English translations would simply be either west or north wind; meanings which become lost in translation. The chapter marries well with the study of the Moqoit by López, where signs can have multiple meanings: when uncovering past or present cosmologies you have to be a deep insider to interpret metaphors that we no longer have words for.

The second part of the book is devoted to case studies, and the editors' introduction to this section ends with their conclusion that "a culture's astronomy reflects the diverse ways people interact with the heavens". This seems to be a rather banal description of cultural astronomy, which in any event should have come earlier because the chapters in the first section gave many examples of how different peoples in different ways interacted with the heavens. Nevertheless, the section begins strongly with a chapter by Frank Prendergast, who considers the journeys of the dead in the Neolithic in relation to the positioning of the Irish passage tombs that have a preference for the northern sector of the horizon. There is a thorough exploration of the concepts of landscape, horizon and skyscape which generates the questions asked of this study, namely whether the vistas of the tombs were intentionally directed towards a "particular horizon range - restricted, intermediate or distant" - and whether these sectors were associated with particular astronomical or symbolic meanings (p. 143). There is a wide-reaching explanation of the methods used to generate the data, such as the techniques of spatial modelling and the parameters to be used, but thankfully the data is condensed into easy to read diagrams and tables. Prendergast must be commended for his knowledge of the existing literature and his ability to recognise that there is much more to cultural astronomy than finding alignments, and he is the only author that shows a willingness to engage with theory, particularly with regard to landscape and place. Questions remain for the editors - this article focuses on methodology and theory, which are inextricably linked, with the actual case study being used as an exemplar, so why is it not in the methodology section?

On to the next case study, which is A. César González García's study of a passage grave at Chabola de la Hechicera in the Rioja Alavesa wine region in Spain, built around 3800 BC. The chamber is oriented too far north for it to be associated with the Sun or 
Moon but it does face the direction of the mountain at Lapoblación, a prominent feature on the local landscape. This monument has seven other passage graves and a dolmen in its vicinity and at all but one out of the total, including Chabola de la Hechicera, the mountain is visible, at times possibly relating to the sunrise between end of April to midAugust. But as the author notes, the evidence is mixed, as they may have been oriented to avoid the prevailing winds, the topography or some other astronomical features not clearly defined. Context is provided by looking at other complexes nearby which are oriented more in line with sunrise. To complete the survey the author looked at other monuments which had been built in the earlier Neolithic. The results are inconclusive but it is nice to see an approach which is wider-ranging than most case studies, which look at monuments or complexes individually.

Efrosyni Boutsikas takes us to the orientations of ancient Greek temples. This is a well-researched topic with inconclusive results in previous studies, but Boutsikas asks a new question, whether the temples' architectural order (Doric, lonic or Corinthian) could have determined their orientation. Consequently, the temples were re-categorised and measured: the data tables, which include 131 temples, take up nine pages, while the analysis of the orientation was spaced out over another three. Interestingly, she found that there seems to be a preference for equinoctial directions, and she points out that the ancient Greeks understood the astronomical equinox and the importance of that time of the year when days and nights are equal, as evidenced by their literature, which emphasised the ideal state of balance and equality (pp. 206-207). As mentioned earlier, this would have been better placed in the Methodology section alongside the other equinox papers.

Robert Hannah also looks at ancient Greece, but his chapter is about the stars and how the Greeks created stories about them, often turning them into gods and goddesses or even sea monsters (p. 214). Their appearance had several uses: navigation; the indication of agricultural seasons; and times to plant and times to harvest. While these were useful practical indicators, Hannah argues that these times were also closely tied with religious festivals, such as those of Demeter and Persephone, and he provides some of the original texts as exemplars. From this he concludes that star risings and settings were not so much observed as calculated (p. 219). Importantly, he concludes that the night sky was "an inseparable part of their perceived environment" (p. 220) and it seems from the case studies in this book that this holds true for the other cultures examined.

Ray Norris and Barnaby Norris stick with the stellar theme in their chapter about the Pleiades. This star cluster is often called the Seven Sisters; in many cultures, including that ancient Greece, they are described as daughters, or in the case of Australian Aborigines as young girls, and both Greek mythology and Aboriginal stories identify Orion as male. In the third century $B C$, according to the Greek poet Aratus, only six of these stars were visible (p. 224), and stories of the "lost" seventh one are found in a wide range of cultures - European, African, Asian, American and so on. There is a long technical dissertation on the astronomy of this cluster in the chapter before we learn more of their mythology. For the Australian Aborigines, learning about the stars is an essential part of their education and the "sisters" appear when hunting, fishing and gathering berries are in season 
(p. 229). The chapter then wanders off to an assessment of which stars are commonly seen by most people and how the physiology of seeing limits what can be seen: this detracts from the much more interesting ethnographical details. Nevertheless, there is an intriguing discussion on why the ancient Greek and Aboriginal stories are so similar, with the suggestion that the "Seven Sisters" story predated the departure of Homo sapiens from Africa in 100,000 BC.

In a volume with such a broad-based agenda it is not a surprise when the next chapter, by Stanislaw Iwaniszewski, takes us to the Mayan Dresden Codex. It focuses on parts of the codices that discuss the Lunar Series and Eclipse Cycles, a unique scheme for lunar reckonings. As Iwaniszewski is one of the leading authorities on Mayan astronomy, his new findings will add to his extensive corpus in this area.

The volume concludes with Part III, "Heritage". Here at last, in the short editorial preface to this section, Ruggles' collaboration with ICOMOS and IAU's Commission C4 on World Heritage and Astronomy is recognised. For those of you who do not know, because it is unexplained, I should point out that ICOMOS stands for International Council on Monuments and Sites and IAU is the acronym for the International Astronomical Union. It should also be pointed out that we put off readers from outside cultural astronomy by assuming everyone understands the language we use, so we need to take more care to make our work more accessible to other disciplines. In a short chapter, Michel Cotte describes how the possibility of a joint venture between ICOMOS and the IAU coincided with the UNESCO and IAU's International Year of Astronomy in 2009, a time when archaeoastronomy was not an important branch in the global field of archaeology (p. 256). He details the considerable hoops that the venture had to jump through to convince a somewhat sceptical audience. Rather strangely, throughout he describes this as a process of preserving "scientific heritage". It seems a rather outdated way to describe cultural heritage sites like Stonehenge or Maeshowe in Britain, which are both UNESCO World Heritage Sites, and unwittingly serves to perpetuate the divide between archaeologists (humanities) and archaeoastronomers (sciences) in the past.

Ivan Ghezzi hones in on one particular heritage site, that of the Chankillo Solar Observatory and Ceremonial Site. The extensive complex was built in Peru c.250-200 $\mathrm{BC}$, using both near and distant natural horizons for astronomical markers. It is a wellresearched site, so this chapter provides a comprehensive and interesting summary of what is known to date, together with some beautiful illustrations. The site features 13 towers, which are believed to be horizon markers for "privileged observers" to track the Sun's seasonal passage throughout the year (p. 267). Additionally, the importance of duality can be determined from the symbolic importance of the towers' dual stairs ( $p$. 269). Though the site clearly indicates the Sun's importance, there is some suggestion that one of the structures references the Moon. Indeed, the site's many features support evidence of further interest in other astronomical observations such as sightlines and light-and-shadow effects (p. 276). The term "observatory" has been open to question (see Belmonte 2015), but here Ghezzi demonstrates that the towers and observing points were specially constructed to be a "precise calendrical instrument" (p. 287). 
The final chapter of the heritage section and the last of the volume is Gudrun Wolfschmidt's exploration of "occidental" observatories in Europe from the Renaissance to the twentieth century. It contains interesting historical details, such as the fact that the octagonal observing room at the Royal Greenwich Observatory in London was built in this shape in order to facilitate observations in all directions (p. 296). Around 1800, some observatories, for example in Italy and Spain, were built in the square shape of the Greek cross. Around the same time other observatories were built with a spherical dome, representing the sky. The popularity of observatories grew so that by 1907 there were 467 sites around the world. Today not many of them are recognised as World Heritage Sites, though the Jodrell Bank Observatory is recognised as "an international icon of science and engineering" (p. 309).

My critique of this book is three-fold and directed to the editors: firstly the extremely poor ordering of the three parts, which has come about perhaps because the hard line they chose between methodology and cases studies is actually blurred. After all, any new research should be conducted after a suitable methodology has been found and explained. Consequently, some case studies delved further into methodology than the chapters deemed to be discussing methodology. Frank Prendergast's detailed explanation of the methodology he used is clear and well-informed. He is also the only author to look at theory, and this is my second concern: in a volume supposedly "advancing" the field, theory is in fact notable by its absence given that Ruggles himself (Ruggles 2011, 1) advocated the need "for our hypotheses to be socially grounded in social theory" ten years ago. This begs the question: why is the Methodology section so titled, rather than as Theory and Methodology? Indeed, the title Advancing Cultural Astronomy surely implies that advances in theory will be particularly highlighted. My third criticism is that the book does not live up to its title, as there is really nothing new, no innovative theory, no ground-breaking methods and less emphasis on interpretation than I had expected: Ruggles' phrase "running around in circles" springs to mind. This is not a critique of the many chapters, most of which do a good job in presenting old familiar sites in a new light, certainly with the result of advancing our specific knowledge of them. Highlights of the volume for me are those chapters by Belmonte, López, Ghezzi, Shipley and Prendergast; however, generally the rest of the content is similar to presentations at cultural astronomy conferences and their subsequent publications. This is the bread-and-butter stuff which keeps the field alive, but to advance it, as promised, you need the jam.

\section{References}

Bailey, M. E., J. A. Cooke, R. W. Few, J. G. Morgan and C. L. N. Ruggles, 1975. “Survey of Three Megalithic Sites in Argyllshire". Nature 253: 431-433. https://doi.org/10.1038/253431a0

Belmonte, J. A., 2015. "Ancient 'Observatories' - A Relevant Concept?". In Handbook of Archaeoastronomy and Ethnoastronomy, edited by C. L. N. Ruggles, 133-145. New York: Springer. https://doi.org/10.1007/9781-4614-6141-8_9

Cooke, J. A., R. W. Few, J. G. Morgan and C. L. N. Ruggles, 1977. “Indicated Declinations at the Callenish Megalithic Sites". Journal for the History of Astronomy 8 (2): 113-133. https://doi.org/10.1177/002182867700800205

Hutton, R. 2013. "The Strange History of Archaeoastronomy". Journal for the Study of Religion, Nature and Culture 7 (4): 376-396. https://doi.org/10.1558/jsrnc.v7i4.376 
Kirch, P. V. and C. L. N. Ruggles, 2019. Heiau, 'Āina, Lani: The Hawaiian Temple System in Ancient Kahikinui and Kaupō, Maui. Honolulu: University of Hawaii Press. https://doi.org/10.1515/9780824879426

Ruggles, C. L. N., 1997. "Whose Equinox?". Archaeoastronomy: Supplement to the Journal for the History of Astronomy 22: S45-S50. https://doi.org/10.1177/002182869702802205

Ruggles, C. L. N., 1999. Astronomy in Prehistoric Britain and Ireland. New Haven, CT: Yale University Press.

Ruggles, C. L. N., 2005. Ancient Astronomy: An Encyclopedia of Cosmologies and Myth. Santa Barbara, CA: ABCCLIO.

Ruggles, C. L. N., 2011. "Pushing Back the Frontiers or Still Running Around in the Same Circles? 'Interpretative Archaeoastronomy' Thirty Years On". In Archaeoastronomy and Ethnoastronomy: Building Bridges between Cultures: Proceedings of the 278th Symposium of the International Astronomical Union and 'Oxford IX' International Symposium on Archaeoastronomy, held in Lima, Peru, January 5-14, 2011, edited by C. L. N. Ruggles, 1-18. Cambridge: Cambridge University Press. https://doi.org/10.1017/S1743921311012427

Ruggles, C. L. N., ed. 2015. Handbook of Archaeoastronomy and Ethnoastronomy. New York: Springer. https:// doi.org/10.1007/978-1-4614-6141-8

Thom, A. and A. S. Thom, 1980. "Astronomical Foresights Used by Megalithic Man". Archaeoastronomy: Supplement to the Journal for the History of Astronomy 11 (2): S90-S94. 